\title{
Stiffness Contributed by Infill to RC Frames using Finite Element Method Approach
}

\author{
Dingari Sreeramya $^{1}$, P. Anuradha ${ }^{2}$ and Dr. N. Murali Krishna ${ }^{3}$ \\ ${ }^{1}$ M. Tech Student, CVR College of Engineering / Civil Engg. Department, Hyderabad, India \\ Email: sreeramyadingari@gmail.com \\ ${ }^{2}$ Research Scholar, Ass. Professor, Osmania University / Civil Engg. Department, Hyderabad, India \\ Email:anuradhaouce@gmail.com \\ ${ }^{3}$ Professor, CVR College of Engineering / Civil Engg. Department, Hyderabad, India \\ Email: nmuralikrishna1956@gmail.com
}

\begin{abstract}
Natural Calamities such as Earthquakes and cyclones cause lateral forces in buildings. Tall Buildings are highly vulnerable to these lateral forces. Designing such buildings to withstand the lateral forces which occur occasionally is considered very expensive. The lateral strength contributed by the infill wall elements is considered to be substantial. Many researchers have adopted different methods to evaluate the lateral strength contributed by wall panels, as on today no complete method has been evolved successfully. In the present work, the lateral strength contributed by the infill panels is explored making use of Finite Element concept. The general purpose of Finite Element package by name MSC NASTRAN is used for the needful calculations. Essentially the Strain Energy contributed by the infill panel in the composite frame structure is equated to the strain energy contributed by an equivalent diagonal strut replacing the infill panel together with bounding frame. Width of such strut is evaluated analytically using MSC NASTRAN. The calculations for strain energy with equivalent diagonal struts is taken-up using STAAD Pro for comparison.
\end{abstract}

Index Terms: Infill, Infill wall, Diagonal Strut, Equivalent Strut, Strain Energy and Lateral Strength.

\section{INTRODUCTION}

From time immemorial, nature's forces have influenced human existence. Even in the face of catastrophic natural phenomena, human beings have tried to control nature and coexist with it. Seismic actions are accidental actions which, depending on the seismicity of the location, rarely occur in the building's design life.

However, because of the destructive power of earthquakes, the stability and safety of buildings located in earthquake-prone areas should be verified for seismic loads. Such verification is based on the results of geological and seismological studies, which provide data on the seismic activity of the location and recommend the values of parameters to be used in the assessment of the expected seismic actions.

It is because of the increased urbanization that a large number of high-raised buildings have appeared. Due to Lack of space, environmental concerns, high cost of manpower, land and architectural constraints, there is need for new and improvised designs for high raised buildings. Natural calamities like earthquakes, typhoons and tsunamis cause a major concern for the stability of these buildings.
In addition, there can also be man-made calamities like accidents and blasts. Thus high-raised buildings are subjected to large shear forces and over turning moments at the base. So now there is a need to not only design the structures to bear vertical loads like Gravity and Imposed loads but also need to take into consideration the different loads due to calamities to avoid loss of life and property.

Shear wall is a vertical plate like RC Walls which starts at foundation and goes through the height of the building. They generally counter the effect of Lateral forces. The specifications are generally developed using design codes. They occupy space and cannot provide parking lots, doors, windows or other functional utilities as the shear wall needs to be a complete vertical wall without any openings.

Thus, we observe reduction in usable area on the shear wall. They are generally not preferred unless necessary for building. So, there is a need for an alternative which performs both as a substitute for shear wall and still has openings required. One such attempt is Infill wall.

Infill frame construction has been in use for more than 200 years. Infill frames are basically associated with the construction of high rise building with the frames carrying the gravity loads. The infill is a means of providing enclosure and internal partitioning to the building. The infill panels were invariably considered to be non-structural. But the behavior of masonry infill frames has been extensively studied in the last five decades in attempts to develop a rational approach for design of such frames.

Infill wall is a wall panel which is bounded by the frame members consisting of beams and columns all around it. Infill concrete frame is the one which includes the infill wall. Infill walls are not only used as partition but also as external walls of the building. It is also used to fill the gap between RC frames. Infill walls are constructed to partition the interior area of buildings to enhance the lateral stiffness of complete structure.

In general infill is considered to be a non-structural element and thus their influence was neglected. The calculation of buildings by modeling of infill walls is complicated. Thus, they are generally ignored during design state. Infill walls are modelled as mass and weight which are 
then applied to floors or beams as a static vertical load and then their effects are calculated. The bearing functionality is achieved by Structure frame while separation of inner and outer space as well as filling up the boxes of the outer frame is achieved by infill. It reduces the probability of collapse due to following reasons

- Lateral deflection of the building.

- Type of Displacement.

- Bending moments in frames.

- Increasing axial forces in columns

\section{LITERATURE REVIEW}

As early as 1960s, studies have been carried out to investigate the influence of infill on the beam column frames under lateral loads induced by earthquakes, wind and blasts. Numerous experimental and analytical investigations have been carried out for the purpose. Nevertheless, a comprehensive conclusion has never been reached due to the complex nature of material properties. Even the infill effect is seen widely but it is not considered explicit in the modern codes.

Sachanski (1960) had considered that the action of infill in an infill frame could be affected by transmitting two components of forces - normal and shear - at a finite number of connecting joints, along the frame/infill interface. He had suggested a theoretical solution considering it as a plane stress problem. [1]

Smith (1962), who had adopted the equivalent diagonal strut concept, had assumed the strut thickness to be the same as that of the infill. He had applied finite difference method to biharmonic equations (expressed in terms of Airy's stress function) to obtain expressions for the Airy's stress function and using the stress-strain plots which help to derive the diagonal stiffness of the infill. [2]

Haroon and Karadi (2012) have performed seismic analysis using Equivalent Lateral Force Method for different reinforced concrete $(\mathrm{RC})$ frame building models that include bay frame, infill frame and open first storey frame. The parameters such as base shear, time period, natural frequency, story drift and bending moments were studied. Here the consideration is done as there is no bond between frame and infill. Equivalent diagonal Strut method is used in modelling the masonry infill panels and ETABS software was used for the analysis of all the frame models. [3]

Stavridis and Shing (2012) presented a simplified analytical method of the seismic performance of masonry infill reinforced concrete frames based on results of an extended analytical and experimental study. The results were used for the validation of finite element model which was able to predict the behavior of the structure. [4]

Akmaluddin et.al. (2012) has done an investigation on the behavior of hybrid reinforced concrete frame with brick masonry infill under static lateral loading. Precast block masonry unit and cast in-place reinforced concrete beams are now termed as hybrid. In this study of frame opening, representing doors and windows are commonly used parameters in the wall system. [5]

Jagadish and Renukadevi (2013) have studied the variation of lateral stiffness and principal compressive diagonal strut width with modulus of masonry infill, with and without openings. In this study non- linear analysis is performed. It was also seen that in case of two frames with equal area of openings, the frame with larger width of opening, exhibits slightly more initial lateral stiffness. [6]

Niranjan C.B et.al. (2013) has observed the changes or variations of stiffness and diagonal strut width with and without openings. As per ANSYS Version 10.0 analysis it is seen that linear analysis of the infill frame over-estimates the lateral stiffness of the infill frame. [7]

K. Lin et al., (2014) developed a new infill masonry system at the University of Newcastle. It uses dry-stacked interlocking bricks. The finite element model for this new system has been developed using the DIANA program. [8]

Lavanya, N. Murali Krishna et.al. (2015) in their paper discussed that the contribution offered from infill walls to the lateral strength of the building is evaluated using a combination of FEM approach and Neural Networks. [9]

Since the integral action of the wall panels with the bounding frame is considered in this approach, the frame is called as infill frame. In this study instead of the infill wall, they considered two diagonal struts joining the opposite corners of the frame.

Ovidiu Bolea (2015) the influence of masonry on global response of reinforced concrete frames is analyzed by using dynamic nonlinear analyses for several structures in the Bucharest area. The results are then discussed with respect to the displacement demand of the elements and masonry behavior. [10] Akash D. Mundaware et.al. (2016) presents that a soft storey of a building frame is analyzed using software package ANSYS. [11]

Narendra A. Kaple et.al. (2016) presents a comparative study on RC building. Spectrum analysis is carried out on a G+6 RCC framed building with bare frame and frame with infill wall using the software ETABS. [12]

Bhavani Shankar et.al. (2016) in his study, has modelled infill wall using interlocking blocks and analyzed the structure using ANSYS software. [13] M.Pradeepkumar (2016) has observed and reviewed from the various research works that there is no doubt that the infill walls contribute in enhancing the structural strength.[14]

In this project, Criteria for earthquake resistant design of structures (IS 1893 (Part 1):2016 and Explanatory handbook on Indian standard code of practice for plain and reinforced concrete (IS 456: 2000) are used as reference for properties. 


\section{METHODOLOGY}

The infill frame that is considered here for developing the flexibility matrix consists of a one bay one storey frame, extending to the left and right by one span and extending to the top and bottom by one storey. The frame members are fixed at their farther ends as shown in the Figure 1.

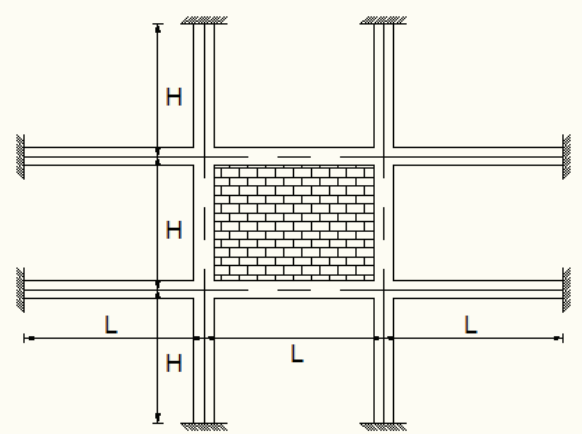

Figure 1. One Bay One Storey Infill frame.

The infill frame is assumed to be made-up with three different materials. While RCC is used for modelling the beam and column members (two-node 3-D frame elements), brick masonry is used to model the infill wall panel (fournode, plane stress quadrilateral elements). The interface between the frame and infill wall panel is modelled with cement mortar (two-node 3-D frame elements).

The infill wall panel is meshed into four-node quadrilateral plane stress elements. The bounding frame members all around the infill have been discretized into number of frame elements to facilitate the connectivity with the corresponding nodes of infill panel. The elements connecting the nodes on infill panel boundary with nodes on the bounding frame elements are called link elements.

While the properties of concrete are taken from IS456:2000 and experiments, the properties of mortar and masonry are taken from different research papers. A unit force is applied in horizontal direction at the top left-hand corner of the infill frame and the linear elastic static analysis module of MSC NASTRAN is run.
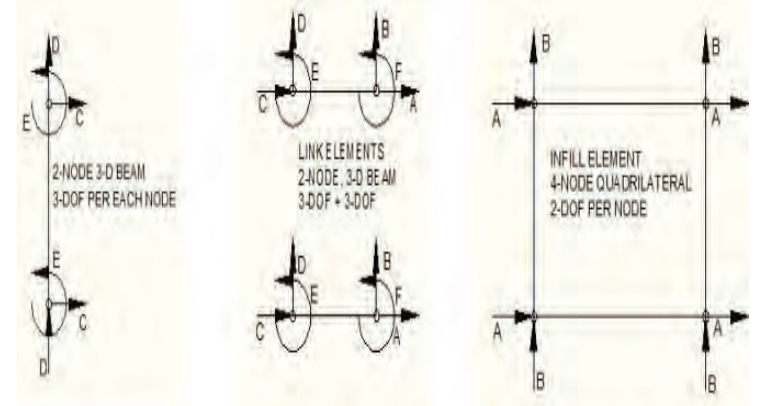

Figure 2. Frame Element, Link Element and Infill Frame (left to right).

The displacements corresponding to three degrees of freedom at the top left-hand corner, top right-hand corner, bottom right hand corner and the bottom left- hand corner are recorded in order, which forms the first column of the flexibility matrix.

The same process is repeated by applying a unit load in turn, corresponding to each degree of freedom. All twelve displacements corresponding to each force application are recorded systematically to form the flexibility matrix of the corresponding frame.

Now the obtained flexibility matrix $(12 * 12)$ is inverted to get the stiffness matrix (K). A displacement vector (d) is defined with unit displacements corresponding to the horizontal force applied at first beam column joint which represents the 1 st column of flexibility matrix. The strain energy for the infill frame (U) is calculated by the expression given below. MATLAB is used for the mathematical Matrix Calculations

$$
\mathbf{U}=1 / 2 * \mathbf{d}^{\mathrm{T} *} \mathbf{K} * \mathbf{d}
$$

Modulus of Elasticity is denoted by E

TABLE I.

MATERIAL PROPERTIES

\begin{tabular}{|c|c|}
\hline Modulus of elasticity of Concrete & $22360 \mathrm{~N} / \mathrm{mm} 2$ \\
\hline Modulus of elasticity of Masonry & $4170 \mathrm{~N} / \mathrm{mm} 2$ \\
\hline Modulus of elasticity of Cement mortar & $2958 \mathrm{~N} / \mathrm{mm} 2$ \\
\hline Poisson's ratio of Concrete & 0.15 \\
\hline Poisson's ratio of Masonry & 0.14 \\
\hline Poisson's ratio of Cement mortar & 0.13 \\
\hline
\end{tabular}

This analysis using MSC NASTRAN is performed for different sizes, specifically $1200 \mathrm{~mm} * 700 \mathrm{~mm}$, $900 \mathrm{~mm} * 700 \mathrm{~mm}$ and $700 \mathrm{~mm} * 1200 \mathrm{~mm}$ in this project and considering various frames as given hereunder

1. Bare Frame

2. Infill Frame

3. Infill Frame with Window Opening

4. Infill Frame with Door Opening

5. Infill Frame with Window and Door Opening.

Same analysis to obtain flexibility matrix using MSC NASTRAN and MATLAB for obtaining Stiffness matrix and Strain Energy are used. Strain Energy values obtained is used for our results and inferences discussed in Section V.

$\begin{array}{ll}\text { Thickness } & -100 \mathrm{~mm} \\ \text { Beam } & -100 \mathrm{~mm}^{*} 100 \mathrm{~mm} \\ \text { Column } & -100 \mathrm{~mm} * 100 \mathrm{~mm} \\ & \\ \text { The Size of Openings } \\ \text { Window } & -0.36 \mathrm{~m}^{*} 0.36 \mathrm{~m} \\ \text { Door } & -0.36 \mathrm{~m}^{*} 0.525 \mathrm{~m}\end{array}$

The infill wall is next replaced with two diagonal struts connecting the opposite corners of frame made in RCC of arbitrary width as shown in the Figure 3. The same process as described above is adopted for 
obtaining the flexibility matrix, stiffness matrix and the strain energy expression. The flexibility influence coefficients are founding using both MSC NASTRAN and STAAD Pro. MATLAB is used for the mathematical Matrix Calculations to obtain stiffness and Strain Energy.

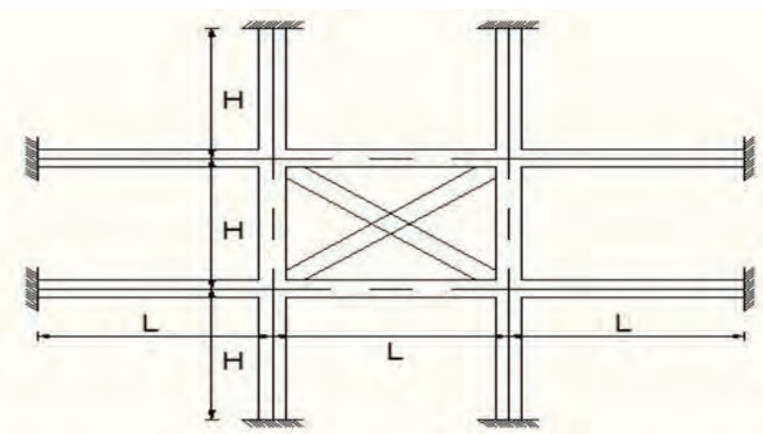

Figure 3. Infill Frame replaced with equivalent diagonal struts.

In general, the value of strain energy obtained is compared with strain energy obtained for the frame with infill. The width of strut is altered depending on the difference in magnitudes of the strain energy with strut until such time that both values of strain energies are matching.

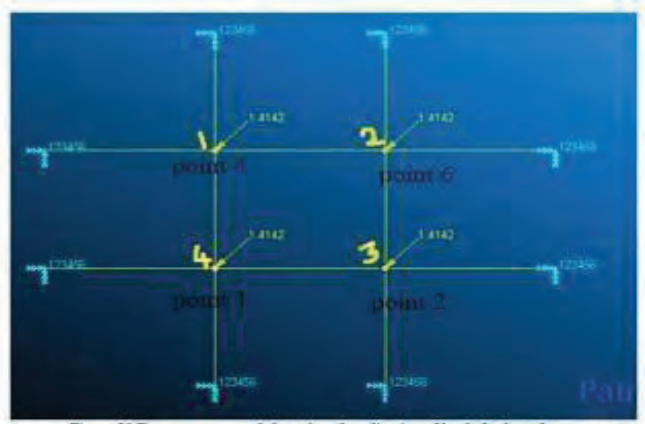

Figure 4. Point of application of loads.

\section{FEM MODELLING}

Frames are analyzed as follows

1. Modelling

2. Creating and Assigning Material Properties

3. Creating and Assigning Support Conditions

4. Creating and Assigning loads

5. Creating the load cases

6. Meshing

7. Analyze

8. Check output files \& Plotting results
Following Frames are analyzed using above method

1. Bare frame subjected to the following loads at all beam column junctions

2. Infill frame subjected to the following loads at all beam column junctions

3. Infill Frame with Window Opening is subjected to the following loads at all beam column junctions

4. Infill Frame with Door Opening is subjected to the following loads at all beam column junctions

5. Infill Frame with Window \& Door Opening is subjected to the following loads at all beam column junctions

- Horizontal point loads

- Vertical point loads

- Rotational point loads

The following pictures are the analytical modelling using MSC NASTRAN which includes five frames with all modelling steps with a clear picture of the mesh seed, mesh and element division. We require only compression members. So we delete all the tension link elements

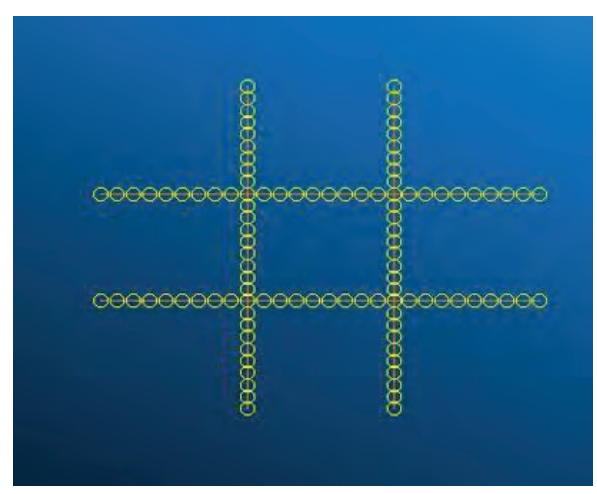

Figure 5. Bare Frame

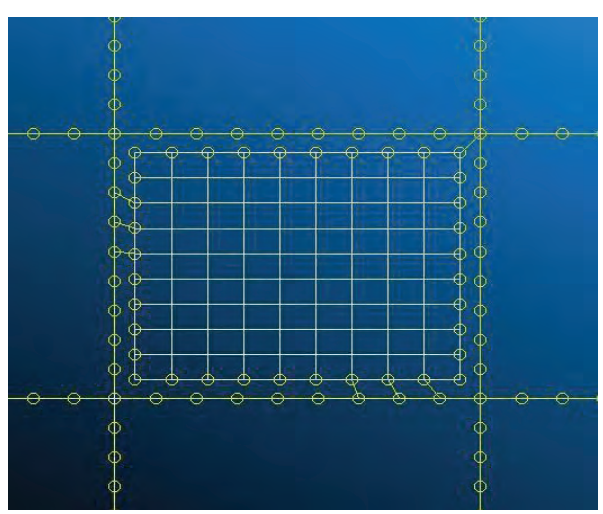

Figure 6. InfillFrame 


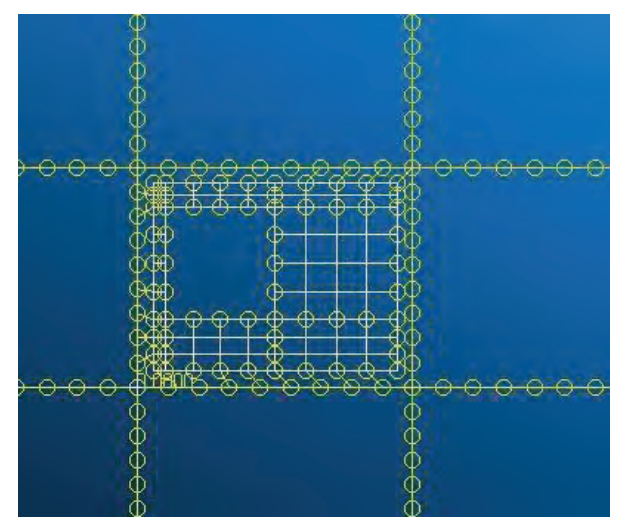

Figure 7. Infill Frame with Window Opening

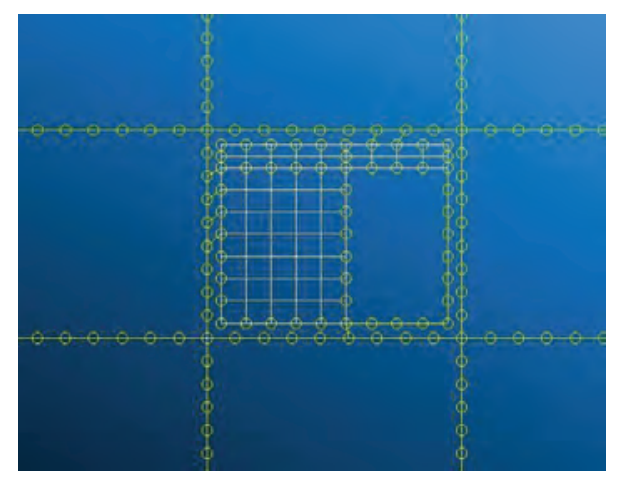

Figure 8. Infill Frame with Door Opening

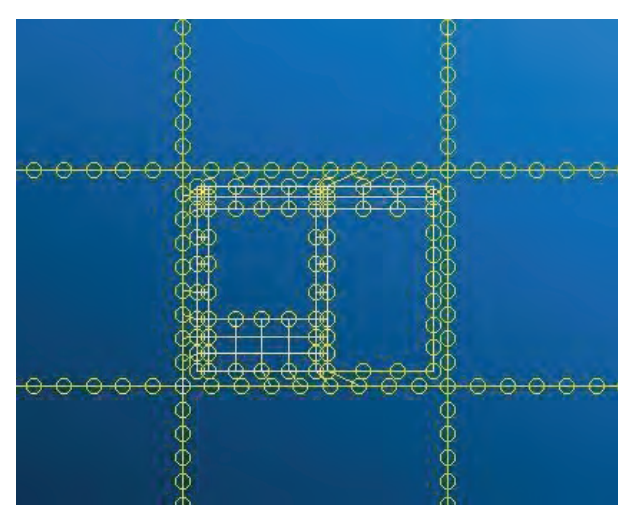

Figure 9. Infill Frame with Window \& Door Opening

Use STAAD Pro for modelling and analysis of Equivalent Diagonal Strut frame which is used to replace the infill and same loading and property conditions are used as in MSC NASTRAN to obtain flexibility matrix. Treating the 2diagonal strut as truss element.

But it is observed that on application of load, one component is in tension and other is in compression. Delete Tension strut and perform analysis with only compression strut.

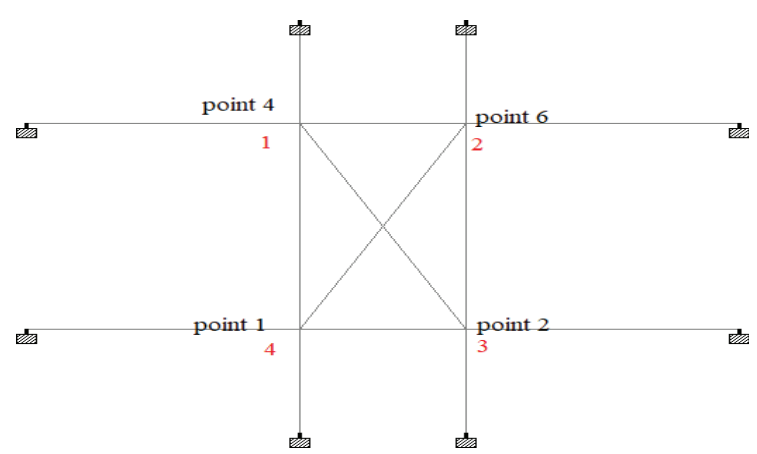

Figure 10. Equivalent Diagonal Strut Frame

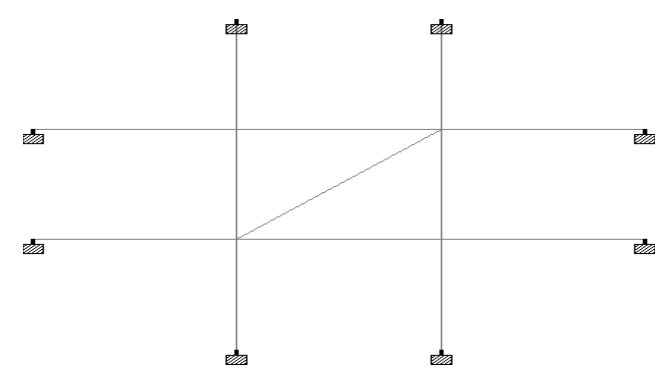

Figure 11. Equivalent Diagonal Strut Condition with Compression Only

As explained in method of study we model the frames and apply loads and obtain a $12 * 12$ Flexibility matrix. For the aspect Ratio $1200 * 700$ and Bare frame a sample $12 * 12$ Flexibility matrix is given below in Table 2

This Flexibility matrix is inversed using MATLAB software where $12 * 12$ Numeric matrix is defined using displacement values obtained from analysis of MSC NASTRAN or STAAD Pro. Then the First column of the flexibility matrix is defined as $\mathrm{d}$ which is $12 * 1$ matrix (Column matrix). Transpose of this matrix is $\mathrm{d}^{\mathrm{T}}$ which is obtained using MATLAB and then calculate strain energy using the equation

$$
\mathrm{U}=1 / 2 * \mathrm{~d}^{\mathrm{T} *} \mathrm{~K} * \mathrm{~d}
$$

For the case of the Equivalent Diagonal Strut first perform MSC NASTRAN analysis for the bare frame and Infill frame for the aspect ratio required. Then using results, calculate Strain Energy as explained above. Then for the same aspect ratio, material properties we perform analysis using STAAD PRO and again calculate Strain Energy as same as above method to observe the results.

Note down the strain energy value and compare that with the infill strain energy which is calculated through NASTRAN package. The requirement here is to equate the infill frame strain energy with the equivalent diagonal strut. By using trial and error method increase or decrease of width (W) of diagonal strut is performed in order to have the same strain energy as that of infill frame. 
TABLE II.

12*12 FLEXIBILITY MATRIX For BARE FrAME - 1200*700 ASPECT RATIO

\begin{tabular}{|c|c|c|c|c|c|c|c|c|c|c|c|}
\hline 1.297E-06 & $-5.214 \mathrm{E}-09$ & 1.145E-08 & $1.141 \mathrm{E}-06$ & $2.276 \mathrm{E}-08$ & 1.159E-09 & $8.486 \mathrm{E}-07$ & $-1.519 E-07$ & 1.696E-09 & $6.682 \mathrm{E}-07$ & $1.500 \mathrm{E}-07$ & $-5.284 \mathrm{E}-09$ \\
\hline $2.080 \mathrm{E}-08$ & $1.723 \mathrm{E}-06$ & 7.395E-10 & $1.954 \mathrm{E}-07$ & $1.639 \mathrm{E}-07$ & $-1.097 \mathrm{E}-09$ & $-1.539 E-07$ & $1.310 \mathrm{E}-07$ & $-1.210 \mathrm{E}-09$ & $-5.357 E-08$ & 1.376E-06 & $-4.305 E-10$ \\
\hline$-2.504 \mathrm{E}-09$ & $-1.136 \mathrm{E}-09$ & $-1.209 E-11$ & $3.385 \mathrm{E}-10$ & 1.070E-09 & $-5.393 E-12$ & $8.024 \mathrm{E}-10$ & $6.581 \mathrm{E}-10$ & $-4.045 E-12$ & 1.400E-09 & $-6.958 \mathrm{E}-10$ & $-1.902 \mathrm{E}-11$ \\
\hline 9.997E-07 & $-1.416 \mathrm{E}-07$ & 8.432E-09 & $1.073 \mathrm{E}-06$ & $1.818 \mathrm{E}-07$ & $1.126 \mathrm{E}-10$ & $9.481 \mathrm{E}-07$ & $-2.679 \mathrm{E}-08$ & $7.564 \mathrm{E}-10$ & 9.393E-07 & $-2.155 E-08$ & $-9.152 E-09$ \\
\hline 3.004E-08 & $1.590 \mathrm{E}-06$ & $6.133 \mathrm{E}-10$ & $1.822 \mathrm{E}-07$ & $1.608 \mathrm{E}-07$ & $-1.109 E-09$ & $-1.952 \mathrm{E}-07$ & $1.409 \mathrm{E}-07$ & $-1.346 \mathrm{E}-09$ & 1.158E-09 & 1.497E-06 & -1.807E-09 \\
\hline$-2.103 E-09$ & $-3.712 \mathrm{E}-11$ & $-1.725 \mathrm{E}-11$ & $-8.206 E-10$ & 7.005E-10 & $-4.721 E-12$ & $-2.252 \mathrm{E}-11$ & 7.904E-10 & $-7.063 E-12$ & 3.174E-09 & $-1.719 E-09$ & $-4.809 E-11$ \\
\hline 1.679E-06 & $1.714 \mathrm{E}-07$ & $1.225 \mathrm{E}-08$ & $1.103 \mathrm{E}-06$ & $-1.442 \mathrm{E}-07$ & $2.044 \mathrm{E}-09$ & $6.769 \mathrm{E}-07$ & $-2.468 \mathrm{E}-07$ & 2.213E-09 & 4.934E-07 & 2.407E-07 & $-3.527 E-09$ \\
\hline$-1.334 \mathrm{E}-07$ & 1.939E-06 & 2.617E-09 & $1.947 \mathrm{E}-07$ & $1.094 \mathrm{E}-07$ & $-5.357 E-10$ & $-4.381 \mathrm{E}-08$ & $6.534 \mathrm{E}-08$ & $-5.145 E-10$ & 5.415E-09 & $1.280 \mathrm{E}-06$ & $-6.698 \mathrm{E}-10$ \\
\hline$-5.214 \mathrm{E}-09$ & $-5.087 E-10$ & 7.063E-11 & $9.337 \mathrm{E}-10$ & $9.041 \mathrm{E}-11$ & 5.127E-12 & 2.705E-09 & $-6.003 E-10$ & $9.213 \mathrm{E}-12$ & $2.182 \mathrm{E}-09$ & 1.204E-09 & $-1.876 \mathrm{E}-11$ \\
\hline 1.410E-06 & 4.911E-07 & $1.210 \mathrm{E}-08$ & $1.074 \mathrm{E}-06$ & $-3.604 \mathrm{E}-07$ & 3.971E-09 & $8.708 \mathrm{E}-07$ & $-4.602 E-07$ & 4.283E-09 & 5.994E-07 & $3.262 \mathrm{E}-07$ & $-4.182 \mathrm{E}-09$ \\
\hline$-1.502 E-07$ & $1.930 \mathrm{E}-06$ & 2.324E-09 & 2.010E-07 & $1.084 \mathrm{E}-07$ & $-4.975 E-10$ & $-4.081 \mathrm{E}-08$ & $6.245 \mathrm{E}-08$ & $-4.790 \mathrm{E}-10$ & 1.160E-08 & $1.290 \mathrm{E}-06$ & $-7.746 \mathrm{E}-10$ \\
\hline 2.171E-09 & $-3.579 E-09$ & $-3.521 \mathrm{E}-12$ & $4.523 \mathrm{E}-10$ & $2.424 \mathrm{E}-09$ & $-2.050 \mathrm{E}-11$ & $-1.810 \mathrm{E}-09$ & 2.287E-09 & $-2.167 E-11$ & $-8.668 \mathrm{E}-10$ & $-9.097 \mathrm{E}-10$ & 4.467E-12 \\
\hline
\end{tabular}

\section{RESULTS AND DISCUSSIONS}

In this Project, the Analysis is performed on three different sizes as specified below
a. $1200 \mathrm{~mm} * 700 \mathrm{~mm}$
b. $900 \mathrm{~mm} * 700 \mathrm{~mm}$
c. $700 \mathrm{~mm} * 1200 \mathrm{~mm}$

For each of the above aspect ratios, the different frames are analyzed in MSC NASTRAN
1. Bare Frame
2. Infill Frame
3. Infill Frame with Window Opening
4. Infill Frame with Door Opening
5. Infill Frame with Window and Door Opening

The results of the analysis are tabulated in Table III.
For the above different sizes, define two frames in STAAD PRO and the results are tabulated in the Table IV just for the purpose of reference.

1. Bare Frame

2. Equivalent Diagonal Strut Frame

Thus, it can be concluded that the width of the equivalent diagonal strut is found to replace the infill in the frame. Width of such strut is calculated in this analysis for different sizes.

The perfect analysis and exact equivalent diagonal strut can be calculated through neural networks concept while generating a $\mathrm{C}++$ program by giving the inputs required to perform and analyze and finally get the required output. That is the width of the equivalent diagonal strut. The abbreviations are defined below

TABLE III.

MSCNASTRANANALYSISRESULTS-STRAINENERGYFORFIVE FRAMES

\begin{tabular}{|c|c|c|c|}
\hline & \multicolumn{3}{|c|}{ Strain Energy Values } \\
\hline Stiffness & Frame 1 & Frame 2 & Frame 3 \\
\hline K & $1200 * 700$ & $900 * 700$ & $700 * 1200$ \\
\hline KE & $1.390 \mathrm{E}-06$ & $1.333 \mathrm{E}-06$ & $1.568 \mathrm{E}-06$ \\
\hline
\end{tabular}

TABLE IV.

StAAD PRo ANALysis RESUlTS - STRAIN ENERGy FOR THE FrAMES

\begin{tabular}{|c|c|c|c|}
\hline & \multicolumn{3}{|c|}{ Strain Energy Values } \\
\hline Stiffness & Frame 1 & Frame 2 & Frame 3 \\
\hline K & $1200 * 700$ & $900 * 700$ & $700 * 1200$ \\
\hline KE & $1.390 \mathrm{E}-06$ & $1.333 \mathrm{E}-06$ & $1.568 \mathrm{E}-06$ \\
\hline
\end{tabular}



K: $\quad$ Strain energy of open frame
KI: Strain energy of frame with full infill
KE: Strain energy of frame with infill replaced with Equivalent diagonal struts.

\section{Conclusions}

- The lateral deflection recorded for RC frame with infill panel was found to be far too less as compared to the lateral deflection without infill. This shows that the lateral stiffness is greatly enhanced due to the presence of infill.

- For the aspect ratio of $1200 * 700$, Strain Energy of Frame model with infill is found to be nearly forty times more than the corresponding frame without infill.

- For the aspect ratio of $700^{*} 1200$, Strain Energy of Frame model with infill is found to be three times more than the corresponding frame without infill.

- The present methodology presents a rational method for determining the width of the diagonal strut instead of the earlier methods, which are mostly empirical in nature.

- The replacement of the equivalent strut in place of the infill Panel greatly simplifies the structural analysis of buildings with infill wall panels.

- More elaborate studies are needed to be carried-out for the determination of diagonal strut width, so that it improves the structural analysis. More rational and the seismic performance of the buildings also improves.

\section{REFERENCES}

[1] Sachanski, S. K., (1960). "Analysis of Earthquake Resistance of Frame Buildings Taking into consideration the Capacity of filling Masonry" Proc. of II World Conf. on Earthquake Engineering III, Japan,2127-2176.

[2] Smith, B.S., (1962). "Lateral Stiffness of Infill Frames" Journal of Structural Division Proc. ASCE, VOL.88,183-199.

[3] Haroon, R.T., \&Karadi, U.N., (2012). "Seismic Analysis of RC Frame Structure with and without Masonry Infill Walls" Proc. International Journal of Natural Sciences, ISSN09760997.

[4] Andreas Stavridis, P. B. Shing et.al (2012). Finite-element modeling of nonlinear behavior of masonry- Infilled RC frames.

[5] Akmaluddin et.al. (2012) - Hybrid reinforced concrete frame building with pumice brick masonry infill under static lateral loading International Journal of Engineering and Technology,2(8):1482-1491.

[6] Renukadevi, M.V., \& Jagadish, K.S., (2013). "Nonlinear Analysis of Infill Frames" Proc. International Journal of Research in Engineering and Technology, eISSN:2321-7308.

[7] Niranjan C.B et.al. (2013) —Non-Linear analysis of infilled framesll, International Journal of Research in Engineering and Technology, Nov2013,24-29

[8] K. Lin et al., (2014) -Modelling of dry- stacked masonry panel confined by reinforced concrete framell, archives of civil and mechanical engineering
[9] V.Lavanyaand N.Muralikrishna et.al. (2015) Analysis of Infill Frames Using Neural Networksll, International Journal of Research in Engineering and Technology (IJRET), 04 (01):110115

[10] Ovidiu Bolea (2015) - The seismic behavior of reinforced concrete frame structures with infill masonry in the Bucharest area, Science Direct, Energy

[11] Akash D. Mundaware et.al. (2016) - Seismic behavior of RC frame building and its analysis with improving measures, International Journal of Advance Research and Innovation, 4(2):1-11.

[12] Narendra A. Kaple et.al. (2016) - Seismic Analysis of RC Frame Structure with and Without Masonry Infill Walls\|, International Conference on Electrical, Electronics, and Optimization Techniques (ICEEOT) -2016,101-106.

[13] Bhavani Shankar et.al. (2016) -Seismic Analysis of Interlocking Block as Infill Wall, International Research Journal of Engineering and Technology (IRJET), 3(10):506512

[14] M.Pradeep Kumar (2016) -Effects of infill wall with and without on RCC frame structure - a reviewll, Imperial Journal of Interdisciplinary Research (IJIR). 